Research Article

\title{
Mortality pattern and trends in surgery wards: a five year retrospective study at a teaching hospital in Hassan district, Karnataka, India
}

\author{
Krishnamurthy V.R., Ishwaraprasad G.D.*, Rajanna B., Samudyatha U.C., Pruthvik B.G.
}

Department of General Surgery, Hassan Institute of Medical Sciences, Hassan, Karnataka, India

Received: 04 July 2016

Accepted: 08 July 2016

*Correspondence:

Dr. Ishwaraprasad G. D.,

E-mail: ishwarprasadgd@gmail.com

Copyright: () the author(s), publisher and licensee Medip Academy. This is an open-access article distributed under the terms of the Creative Commons Attribution Non-Commercial License, which permits unrestricted non-commercial use, distribution, and reproduction in any medium, provided the original work is properly cited.

\begin{abstract}
Background: Information about pattern and cause of death is an important set of health information system, needed for deciding on possible intervention strategies. This study was undertaken with the objective to identify number of deaths in surgical wards for a period of five years and to elicit the causes and pattern of deaths among both operated and non-operated patients.

Methods: A retrospective descriptive study was done on all patients admitted to surgery department of Hassan Institute of Medical Sciences teaching hospital in Hassan District, Karnataka, India from 1st January 2011 to 31 st December 2015. Of all the admissions, data of expired patients in detail were extracted. Extracted data included age, gender, surgical diagnosis, co-morbid conditions, procedure performed, events leading to death and the clinical cause of death.

Results: During the study period, there were 8962 admissions in all the surgery wards; of which 5540 were males and 3422 females. There were 585 deaths with an overall death per admission crude mortality rate of $6.5 \%$. The leading causes of death were road traffic accidents with head injury $(27.86 \%)$ followed by burns $(27.17 \%)$ and GIT related complications (21.02\%). Of the 585 deaths, males were $371(72.79 \%)$ and females $214(27.21 \%)$ in a ratio of $1.73: 1$.

Conclusions: Over the study period reduction in death rate was observed. This reduction was mainly among preventable causes of death like sepsis, trauma and GIT related causes.
\end{abstract}

Keywords: In-hospital surgical mortality, Tertiary care, Cause of death, Retrospective study

\section{INTRODUCTION}

Death is a part of living but doctors have a responsibility towards reducing the mortality of patients to the maximum extent, especially in the surgical field where the outcomes of mortality are decided sometimes by decisions taken by the surgeon.

By analyzing the mortalities, doctors hope to identify the major reasons for death in surgical wards. So that they can devise strategies to preempt and hence prevent the terminal events leading to the expiry of any given patient. ${ }^{1,2}$
Mortality during surgical care may result directly from the pathologic process necessitating surgical care, as a complication of a surgical procedure and anesthesia, or other co-morbid factors. A study of the mortality pattern can help bridge knowledge gaps in a particular surgical setting and can identify areas of care that require more education, practice modification, and/or policy formulation. ${ }^{3}$

Many researchers have tried to do a systematic review of surgical death. There are many reports of similar work in the west and even from African nations. Studies done by Anelechi B et al, Babatunde A et al from Nigeria, Wasim 
$\mathrm{H}$ et al and Ozdemir BA et al, have shown mortality rate in the surgical wards as $9.14 \%, 5.09 \%, 16.1 \%$ and $4.2 \%$ respectively. ${ }^{2-5}$ However such reports from India are few and far.

The results of the present study will help to improve the quality of care by educating the health care professionals about preventable deaths and to suggest the administration for infrastructure strengthening. The basic aim of any surgical procedure is reduction in morbidity and mortality rates. By comparing the influence on adverse outcome; assessment of the efficiency of surgical procedure and the quality of care provided can be done. ${ }^{6}$

Hence this study was undertaken with the objective to identify the deaths in surgical wards for a period of five years and to elicit the causes and pattern of deaths among both operated and non-operated surgical patients and also to suggest changes that will ensure improved surgical care of patients and better outcome.

\section{METHODS}

A retrospective descriptive observational study was done on all patients admitted to the surgery department of HIMS teaching hospital in Hassan District, Karnataka, India. The study period was from $1^{\text {st }}$ January 2011 to $31^{\text {st }}$ December 2015. The hospital is a tertiary referral government teaching hospital. Retrospectively all patients admitted to surgery wards during the 5 year study period were included in the study.

Data for the study was obtained from the case documents from the medical records section. Records were collected from the operation theatre registers and case notes of all patients who were admitted into the surgical wards including elective or emergency admissions. We have excluded the patients who succumbed in emergency room. A minimum of two hours of hospitalization was required to be included in this study.

Out of all the admissions, data of expired patients in detail using proforma sheet have extracted. Extracted data included age, gender, surgical diagnosis, co-morbid conditions, time between onset of symptoms and admissions, procedure performed, events leading to death, dates of death and the clinical cause of death. Case definition of in-hospital surgical mortality which was included in the study was deaths occurring within 30 days of admission for surgical care which has been traditionally used in other studies. ${ }^{3}$

Statistical analysis was done using Microsoft Excel for data entry, Epi Info software for analysis and descriptive statistics to summarize the data.

\section{RESULTS}

Between the years 2011 and 2015 there were 8962 admissions to surgical wards. Men admissions was 5540 (61.82\%) and women 3422 (38.18\%). Among them, 585 deaths occurred in the same period. Of the 585 deaths, 371 were males $(63.41 \%)$ and 214 were females $(36.58 \%$ ) in a ratio of $1.73: 1$ (Table 1,2 and Figure 1).

Table 1: Distribution of year wise mortality rate.

\begin{tabular}{|llll|}
\hline Year & Admissions & Deaths & Mortality rate(\%) \\
\hline 2011 & 1694 & 148 & 8.74 \\
\hline 2012 & 1193 & 133 & 11.15 \\
\hline 2013 & 2291 & 114 & 4.97 \\
\hline 2014 & 1597 & 106 & 6.64 \\
\hline 2015 & 2187 & 84 & 3.84 \\
\hline Total & 8962 & 585 & 6.5 \\
\hline
\end{tabular}

Table 2: Gender specific mortality rates.

\begin{tabular}{|llllllllll|}
\hline Year & Admissions & $\begin{array}{l}\text { Males } \\
\text { admissions }\end{array}$ & $\begin{array}{l}\text { Male } \\
\text { death }\end{array}$ & $\begin{array}{l}\text { Gender } \\
\text { specific } \\
\text { death rate } \\
\text { (males) }\end{array}$ & $\begin{array}{l}\text { Females } \\
\text { admissions }\end{array}$ & $\begin{array}{l}\text { Female } \\
\text { death }\end{array}$ & $\begin{array}{l}\text { Gender } \\
\text { death } \\
\text { rate } \\
\text { (females) }\end{array}$ & $\begin{array}{l}\text { Deaths } \\
\text { Demic }\end{array}$ & $\begin{array}{l}\text { Mortality } \\
\text { rate } \%\end{array}$ \\
\hline 2011 & 1694 & 959 & 92 & 9.59 & 735 & 56 & 7.62 & 148 & 8.74 \\
\hline 2012 & 1193 & 763 & 90 & 11.79 & 430 & 43 & 10 & 133 & 11.15 \\
\hline 2013 & 2291 & 1516 & 79 & 5.21 & 775 & 35 & 4.52 & 114 & 4.97 \\
\hline 2014 & 1597 & 1032 & 68 & 6.59 & 565 & 38 & 6.73 & 106 & 6.64 \\
\hline 2015 & 2187 & 1270 & 42 & 3.31 & 917 & 42 & 4.59 & 84 & 3.84 \\
\hline Total & 8962 & 5540 & 371 & 6.7 & 3422 & 214 & 6.25 & 585 & 6.5 \\
\hline
\end{tabular}

The gender specific death rate was $6.70 \%$ (371 out of 5540 ) and $6.25 \%$ (214 out of 3422) for men and women respectively. Table 3 shows the age distribution as well as the number of deaths in each gender. Majority of these $373(63.76 \%)$ mortalities were among the individuals who were below 50 years of age. The study shows a 
progressive decreasing mortality trend from 2011 to 2015 from $25.29 \%$ to $14.35 \%$ i.e., a reduction of $10.94 \%$ in absolute figures (43.2\% reduction in relative figures) (Table 4). It also shows that reduction in mortality among men is $13.47 \%$ and among women is $6.54 \%$ (absolute figures). The most common cause being RTA with head injury $(27.86 \%)$ followed by burns $(27.17 \%)$ and GIT related complications $(21.02 \%)$ (Table 5).

Table 3: Proportional mortality rate by age during the period 2011-2015.

\begin{tabular}{|lllll|}
\hline Distribution of death (according to age in years) & \multicolumn{4}{l}{ Number of death during the period 2011- 2015 } \\
& Female & Male & Total & Percentage \\
\hline $1-10$ & 2 & 4 & 6 & 01.02 \\
\hline $11-20$ & 16 & 14 & 30 & 05.12 \\
\hline $21-30$ & 57 & 55 & 112 & 19.15 \\
\hline $31-40$ & 35 & 73 & 108 & 18.46 \\
\hline $41-50$ & 33 & 84 & 117 & 20.00 \\
\hline $51-60$ & 16 & 58 & 74 & 08.03 \\
\hline $61-70$ & 46 & 53 & 99 & 16.92 \\
\hline $71-80$ & 8 & 17 & 25 & 04.27 \\
\hline $81-90$ & 1 & 13 & 14 & 02.39 \\
\hline Total & 214 & 371 & 585 & 100 \\
\hline
\end{tabular}

Table 4: Year-wise distribution of causes of death among patients admitted to surgical wards during the period 2011-2015.

\begin{tabular}{|c|c|c|c|c|c|c|c|c|}
\hline \multirow[b]{2}{*}{ Gender } & & \multicolumn{6}{|c|}{ Cause of death during the period 2011-2015 } & \multirow[t]{2}{*}{ Total } \\
\hline & Year & $\begin{array}{l}\text { GIT } \\
\text { related } *\end{array}$ & $\begin{array}{l}\text { RTA } \\
\text { with } \\
\text { head } \\
\text { injury }\end{array}$ & $\begin{array}{l}\text { RTA chest/ } \\
\text { polytrauma }\end{array}$ & Malignancy & Burns & $\begin{array}{l}\text { Non GIT } \\
\text { septicemia and } \\
\text { others }^{\#}\end{array}$ & \\
\hline \multirow{6}{*}{ Female } & 2011 & 9 & 12 & 3 & 5 & 21 & 6 & 56 \\
\hline & 2012 & 7 & 3 & 0 & 2 & 24 & 7 & 43 \\
\hline & 2013 & 2 & 5 & 1 & 1 & 22 & 4 & 35 \\
\hline & 2014 & 6 & 7 & 0 & 3 & 14 & 8 & 38 \\
\hline & 2015 & 0 & 12 & 0 & 2 & 24 & 4 & 42 \\
\hline & Total & 24 & 39 & 4 & 13 & 105 & 29 & 214 \\
\hline \multirow{6}{*}{ Male } & 2011 & 26 & 26 & 9 & 2 & 11 & 18 & 92 \\
\hline & 2012 & 24 & 28 & 14 & 4 & 9 & 11 & 90 \\
\hline & 2013 & 28 & 28 & 4 & 2 & 12 & 5 & 79 \\
\hline & 2014 & 9 & 30 & 2 & 1 & 12 & 14 & 68 \\
\hline & 2015 & 12 & 12 & 0 & 2 & 10 & 6 & 42 \\
\hline & Total & 99 & 124 & 29 & 11 & 54 & 54 & 371 \\
\hline \multirow{6}{*}{$\begin{array}{l}\text { Both male and } \\
\text { female }\end{array}$} & 2011 & 35 & 38 & 12 & 7 & 32 & 24 & 148 \\
\hline & 2012 & 31 & 31 & 14 & 6 & 33 & 18 & 133 \\
\hline & 2013 & 30 & 33 & 5 & 3 & 34 & 9 & 114 \\
\hline & 2014 & 15 & 37 & 2 & 4 & 26 & 22 & 106 \\
\hline & 2015 & 12 & 24 & 0 & 4 & 34 & 10 & 84 \\
\hline & Total & 123 & 163 & 33 & 24 & 159 & 83 & 585 \\
\hline
\end{tabular}

Table 5: Surgical diagnosis/cause of death.

\begin{tabular}{|lll|}
\hline Surgical diagnosis/Cause of death & Frequency & Percentage (\%) \\
\hline GIT related- perforated peritonitis, upper GI bleed & 123 & 21.02 \\
\hline RTA with head injury & 163 & 27.86 \\
\hline RTA c chest/ Polytrauma & 33 & 05.64 \\
\hline Malignancy & 24 & 04.10 \\
\hline Burns & 159 & 27.17 \\
\hline Non GIT Septicemia- DM and others & 83 & 14.18 \\
\hline Total & 585 & 100 \\
\hline
\end{tabular}




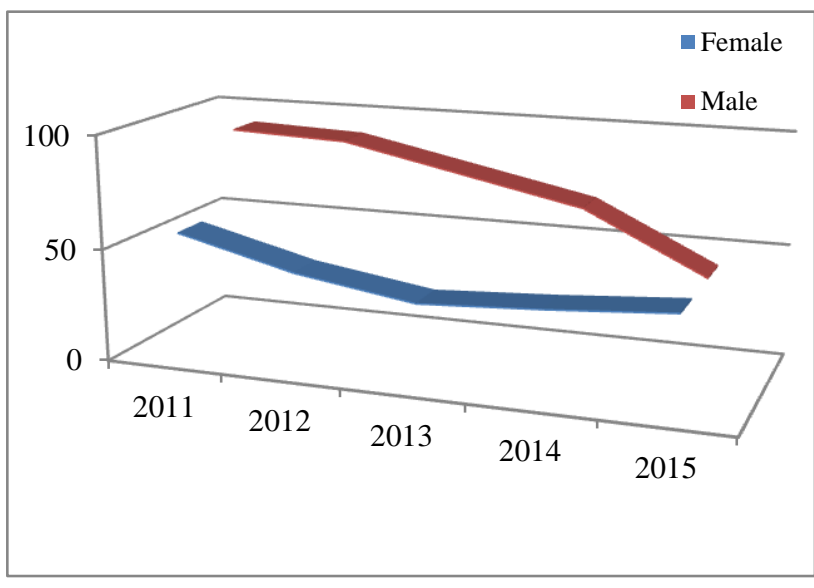

Figure 1: Gender and year wise distribution of deaths.

\section{DISCUSSION}

Death in hospital often has disastrous consequences and reflects the quality of surgical services. It draws attention from the public, media and administration. Also it adds to the occupational stress among surgeons. Many a time surgical deaths occur when it is least expected unlike medical wards.

Finding out the cause of death would help us gain an insight into the measures that can be applied to reduce mortality and improve the overall outcome. Records of vital events like death constitute an important component of the health information system. ${ }^{7}$

The district hospital attached to the institution was only a service hospital prior to 2006. The first batch of interns was added to provide service in 2011. From 2011 through 2015 there is a zigzag trend in number of patients admitted to the hospital. Among them surgical mortality rate of $6.5 \%$. This observation in present study compares reasonably with many studies from authors Anelechi B et al, Wasim Hayat et al, Ihegihu $\mathrm{CC}$ et al, Ekeke $\mathrm{ON}$ et al $9.14 \%, 6.2 \%, 8.3 \% 6.4 \%$ respectively. ${ }^{2,4,9,10}$

There is a steady decrease in absolute number of deaths. However there is varying trend in the crude death rates; though there is a general declining trend in the death rate as well. Many studies worldwide have shown a similar decrease in the death rates among surgical ward patients. ${ }^{4}$

Men were almost double the number of women among the dead (63\% v/s 37\%). Many authors have found preponderance of male deaths over female deaths similar to our study. ${ }^{2,4,8,7}$ Traditionally men make up two thirds of the surgical patients compared to women. The death rate is almost same as the admission rate $(62 \% \mathrm{v} / \mathrm{s} 38 \%)$. Over the study period both gender showed reduction in deaths. However reduction in death is almost twice among men compared to women. This reduction is mainly among preventable causes like sepsis, trauma and
GIT related causes, which were the leading causes of death in men.

Majority of deaths were noted in the $3^{\text {rd }}, 4^{\text {th }}$ and $5^{\text {th }}$ decade of life with the peak occurring at $5^{\text {th }}$ decade. This observation is similar to majority of the studies. ${ }^{2-4}$ Death in this productive age group adds to the burden of the family and society. It is observed that surgical deaths peak a decade or two earlier than medical deaths. ${ }^{7}$ Another peak noted in $7^{\text {th }}$ decade when malignancy and co morbid conditions contribute to the death. Neglect by the family may also contribute to the increased mortality in this group. ${ }^{7}$ Deaths among women occur more frequently in $2^{\text {nd }}$ and $3^{\text {rd }}$ decade with a second peak in $7^{\text {th }}$ decade similar to men.

More than half of the deaths ( 314 out of $585=54 \%$ ) were due to trauma as a broad category. This included burns and non-burn trauma contributing almost equally. RTA with head injury and chest injury was the leading cause of death among men, while burn was the predominant cause of death among women. As the burn injuries are due to marital discord and domestic problems, they were more common among women at late $2^{\text {nd }}$ and $3^{\text {rd }}$ decade, whereas RTA was more common among men found mostly in the actively mobile group of $3^{\text {rd }}, 4^{\text {th }}$ and $5^{\text {th }}$ decade.

Improving the standards of our health care facilities and personnel would further prevent these deaths. Thompson et al and Anelechi B et al suggested that through continuous peer review audit will contribute to changes in surgical and anaesthetic practice so that the rate of adverse events can be decreased by changing clinical practice. ${ }^{4,11}$

Mortality due to burns should encourage the administration to establish specialized burn units under the care of a dedicated plastic and burn surgeon. It is also time to establish full pledged trauma care unit with neurosurgeon included. Both are currently in the focus of National health policy of Govt. of India. ${ }^{12,13}$

Further there is need for regular audit of deaths and problems of documentations should be addressed. The death notes should be revised and develops a userfriendly computer based data. This should include details of age, gender, place of residence, surgical diagnosis, comorbid conditions, time between onset of symptoms and admissions, procedure performed, events leading to death, dates of death and the clinical cause of death.

Limitation of the study could be it's a retrospective study; admission to death ratio may not be the exact number because of error in documentation etc. Few of the case sheets we could not get complete details. 


\section{ACKNOWLEDGEMENTS}

Authors are thankful to all staff of records department for their co- operation.

Funding: No funding sources

Conflict of interest: None declared

Ethical approval: The study was approved by the institutional ethics committee

\section{REFERENCES}

1. Nixon SJ. Deaths following miscellaneous abdominal/hernia surgery. Scottish audit of surgical mortality annual report 1996. royal college of physicians and surgeons, Glasgow, 1997:39-40.

2. Wasim Hayat, Fraz Fahim M, Arshad Cheema. Mortality analysis of a surgical unit. Biomedica New Journal. 2004;20:96-8.

3. Babatunde A, Ayoade LO. Thanni OSO. Mortality pattern in surgical wards of a university teaching hospital in southwest Nigeria: a review. World J Surg. 2013;37:504-9.

4. Anelechi B, Chukuezi A, Jones N, Nwosu. Mortality pattern in the surgical wards: a five year review at federal medical centre, Owerri, Nigeria. Int J Surg. 2010;8:381-3.

5. Ozdemir BA, Sinha S, Karthikesalingam A, Poloniecki JD, Pearse RM, Grocott MPW, et al. Mortality of emergency general surgical patients and associations with hospital structures and processes. Br J Anaes. 2016;116(1):54-62.
6. Vallabha T, Manish P. Assessment of surgical outcome in general surgery using portsmouth possum scoring. Al Ameen $J$ Med Sci. 2013;6(1):65-9.

7. Godale L, Mulaje S. Mortality trend and pattern in tertiary care hospital of solapur in Maharastra. Indian J Community Medicine. 2013;38:49-52.

8. Kulkarni SK, Doibale MK. Mortality trend in tertiary care hospital of nanded in Maharashtra. Int $\mathbf{J}$ Basic Applied Med Sci. 2014;4(1):372-3.

9. Ihegihu CC, Chianakwana GU, Ugezu T, Anyanwu SNC. A review of in-hospital surgical mortality at the Nnamdi Azikiwe University teaching hospital, Nnewi, Nigeria. Tropical J Med Res. 2007;11(2):2630.

10. Ekeke ON, Okonta KE, Igwe PO. Surgical inpatient mortality in a Nigerian tertiary hospital. Niger J Clin Pract. 2016;19:308-12.

11. Thompson AM, Ashraf Z, Burton H, Stonebridge PA. Mapping changes in surgical mortality over 9 years by peer review audit. $\mathrm{Br} \mathrm{J}$ Surg. 2005;92(11):1449-52.

12. Government of India, National health mission: Ministry of health and family welfare. Operational guidelines for establishment of burn unit in district hospital under NPPMBI.2015:1-18.

13. Government of India, National health mission: Ministry of health and family welfare other national programme. Capacity building for developing trauma care facilities in Govt. hospitals on National highways. Annual Report. 2014;15:176-9.

Cite this article as: Krishnamurthy VR, Ishwaraprasad GD, Rajanna B, Samudyatha UC, Pruthvik BG. Mortality pattern and trends in surgery wards: a five year retrospective study at a teaching hospital in Hassan district, Karnataka, India. Int Surg J 2016;3:1125-9. 